\title{
Anti-obesity and hepatoprotective effects in obese rats fed diets supplemented with fruit purees
}

\author{
Úrsula Mireya MORALES-ÁVILA', Eduardo Mendeleev BECERRA-VERDÍN², \\ Sonia GUADALUPE SÁYAGO-AYERDI ${ }^{1}$, John P. TOLMAN³, Efigenia MONTALVO-GONZÁLEZ ${ }^{\text {* }}$
}

\begin{abstract}
In this work, the effect of the intake of a low-fat diet supplemented with a fruit puree (guava-strawberry, guava-blackberry, guava-soursop or guava-passion fruit) by obese rats on reduction of body weight, lipid profile, and liver enzyme activity was evaluated. The rats ( $\mathrm{n}=6$ for each treatment) were induced to obesity with a high-fat diet for 4 weeks, then they were fed with a low-fat diet plus a fruit puree for 4 weeks. Healthy rats and obese rats fed with standard diet as controls were considered. The additional consumption of fruit purees was associated with a reduction in body weight (16-24\%), a control in the metabolism of plasma lipids decreasing the levels of total cholesterol (59-68\%) and triacylglycerols (61-82\%). We found a significant reduction in inflammation markers and liver damage; enzyme activity (alanine aminotransaminase, aspartate aminotransferase, $\gamma$-glutamyl transferase and alkaline phosphatase) decreased, and a notable improvement in liver morphology was observed. The consumption of fruit purees by obese individuals could contribute to the control of and improvement in the complications of obesity caused by alterations in lipoproteins.
\end{abstract}

Keywords: fruit purees; anti-obesity; liver enzymes; hepatoprotective.

Practical Application: The processed fruit purees are an alternative for prevention and control of obesity.

\section{Introduction}

In the last 4 years in Mexico, the number of overweight (75.2\%) and obese (36.3\%) individuals, both adults and young people, has increased according to the results of the National Health and Nutrition Survey-Mexico (Encuesta Nacional de Salud y Nutrición, 2016). Obese individuals generate high levels of circulating fatty acids, principally triacylglycerols. These free cortical fatty acids cause insulin resistance. Insulin resistance also results in the inhibition of hepatic gluconeogenesis and absorption of glucose by muscle and adipose tissue, thus initiating the systemic inflammatory process, which causes changes in metabolites circulating in the serum and the development of hepatic steatosis (Ding et al., 2016). This is a result of an increasing concentration of intracellular enzymes such as aspartate aminotransferase (AST), alanine aminotransaminase (ALT), alkaline phosphatase (ALP), $\gamma$-glutamyltransferase (GGT), among others (Wang, 2015).

Bioactive compounds such as dietary fiber, phenolic compounds, carotenoids, vitamins and minerals that are consumed from fruits and vegetables can control or have the ability to reduce these markers of metabolic risk (Dongiovanni et al., 2016). However, the functional potential of processed foods containing a combination of fruits has rarely been studied. We investigated the effect of intake of fruit purees on biochemical markers in hypercholesterolemic rats and we demonstrated that all purees decreased total cholesterol and triacylglycerols in hypercholesterolemic rats (Pérez-Beltrán et al., 2017). Therefore, derived of our first study and that we did not induce obese rats, we hypothesized that the consumption of fruit purees would have an anti-obesity effect and to cause a hepatoprotective effect in obese rats. Therefore, aim of this work was to evaluate the effects of the intake of fruit purees on liver biomarkers to evaluate hepatoprotective activity and reduction in body weight in obese rats.

\section{Materials and methods}

\subsection{Fruit purees}

Four puree formulations, guava-strawberry (GSP), guava-blackberry (GBP), guava-soursop (GSSP) and guava-passion fruit (GPP) purees, were donated by Purés y Derivados de Nayarit (PDN), Camichin de Jauja, Nayarit, Mexico. The elaboration, characteristics, nutritional composition and content of bioactive compounds of the purees were described in a previous publication (Pérez-Beltrán et al., 2017).

\subsection{Experimental diets}

Six diets were used. A commercial pedestrian maintenance diet for experimentation (Nutri cubo Purina ${ }^{\circledR}$; Agribands Purina Mexico SA de CV., Mexico City, Mexico) was considered as the standard rodent diet (StD). Other diet was a high-fat diet 
(HF-StD), which was prepared using StD (50\%) and it was fried for 20 min with commercial pork lard (50\%), this diet only was used for obesity induction. Other four diets were prepared with $\mathrm{StD}$ without frying (86.6\%) more each type of fruit puree (13.3\%) and these diets were used as anti-obesity and hepatoproptective treatments. The nutritional composition of diets was evaluated (Supplementary Material, Table S1).

\subsection{Animals and experimental design}

The State Bioethics Committee of Nayarit, Mexico, approved the experimental protocol ( $\mathrm{n}^{\circ}$. CENB/03/2017) and the protocols of the Institutional Animal Care and Use Committee according to Mexican law (Norma Oficial Mexicana, 1999) were followed. Thirty-six adult female Wistar rats $(245 \pm 5 \mathrm{~g})$, with age of 2 months, were obtained from the Institute of Neurobiology of Universidad Autónoma de México (Queretaro, Mexico). They were placed in individual cages and kept under normal conditions of humidity $(60 \pm 10 \%)$ and temperature $\left(23 \pm 1{ }^{\circ} \mathrm{C}\right)$, with $12 \mathrm{~h}$ periods of light and dark. The animals were fed with StD and water ad libitum. After 1 week of acclimation, the animals were randomized into six groups of six rats each (Figure 1). The healthy control group was fed with $15 \mathrm{~g} \mathrm{StD}$ and water ad libitum during all the experiment. To induce obesity, the rats were fed with HF-StD for 8 weeks; after induction of obesity the rats were weighted, the HF-StD diet was removed and obese rats were divided in five groups to their feeding. The groups were as follows: Group I: healthy control group fed with StD (StD); Group II: obese group fed with StD (Ob-StD); Group III: obese group fed with StD + guava-strawberry puree (Ob-StD + GSP); Group IV: obese group fed with $\mathrm{StD}+$ guava-blackberry puree $(\mathrm{Ob}-\mathrm{StD}+\mathrm{GBP})$; Group V: obese group fed with StD + guava-soursop fruit puree (Ob-StD + GSSP); Group VI: obese group fed with StD + guava-passion fruit puree (Ob-StD + GPP). Over the dietary intervention period, the diets and water were administrated orally ad libitum. The quantities of diet every day for 4 weeks more were: $15 \mathrm{~g}$ StD to H-StD group and DM-StD group and $13 \mathrm{~g}$ StD mixed with $2 \mathrm{~g}$ of a different fruit puree to the others obese rats. The food intake of the rats was recorded daily, and their body weights were monitored each week throughout the experiment. After, the animals were killed after $12 \mathrm{~h}$ of fasting to obtain blood and hepatic tissue. The euthanasia protocol according to the Manual on the Use and Care of Experimental Animals (Norma Oficial Mexicana, 1999) was followed. The blood samples were obtained from the inferior vena cava. Serum samples were obtained by centrifuging the blood samples $(1.5 \mathrm{~mL})$ at $4500 \mathrm{xg}$ for $5 \mathrm{~min}$ at $4{ }^{\circ} \mathrm{C}$, and were analyzed within $7 \mathrm{~h}$ in order to comply with the quality control requirements of clinical biochemical tests.

\subsection{Biochemical markers}

The enzyme activity of AST, ALT, GGT and ALP, and the concentration of glucose, urea, creatinine, uric acid, total proteins, albumin and bilirubin as well as total cholesterol (TC), triacylglycerols (TG) and high-density lipoprotein cholesterol (HDL-C) were determined in the serum samples using enzymatic kits (Biosystems Reagents and Instruments, Barcelona, Spain) performed according to the manufacturers' instructions and a calibrated BTS-350 Biosystem Auto-analyzer, (Biosystems Reagents and Instruments, Barcelona, Spain). The low-density lipoprotein cholesterol (LDL-C) and very-low-density lipoprotein cholesterol (VLDL-C) fractions were determined according to the Friedewald equations (Siri-Tarino \& Krauss, 2016).

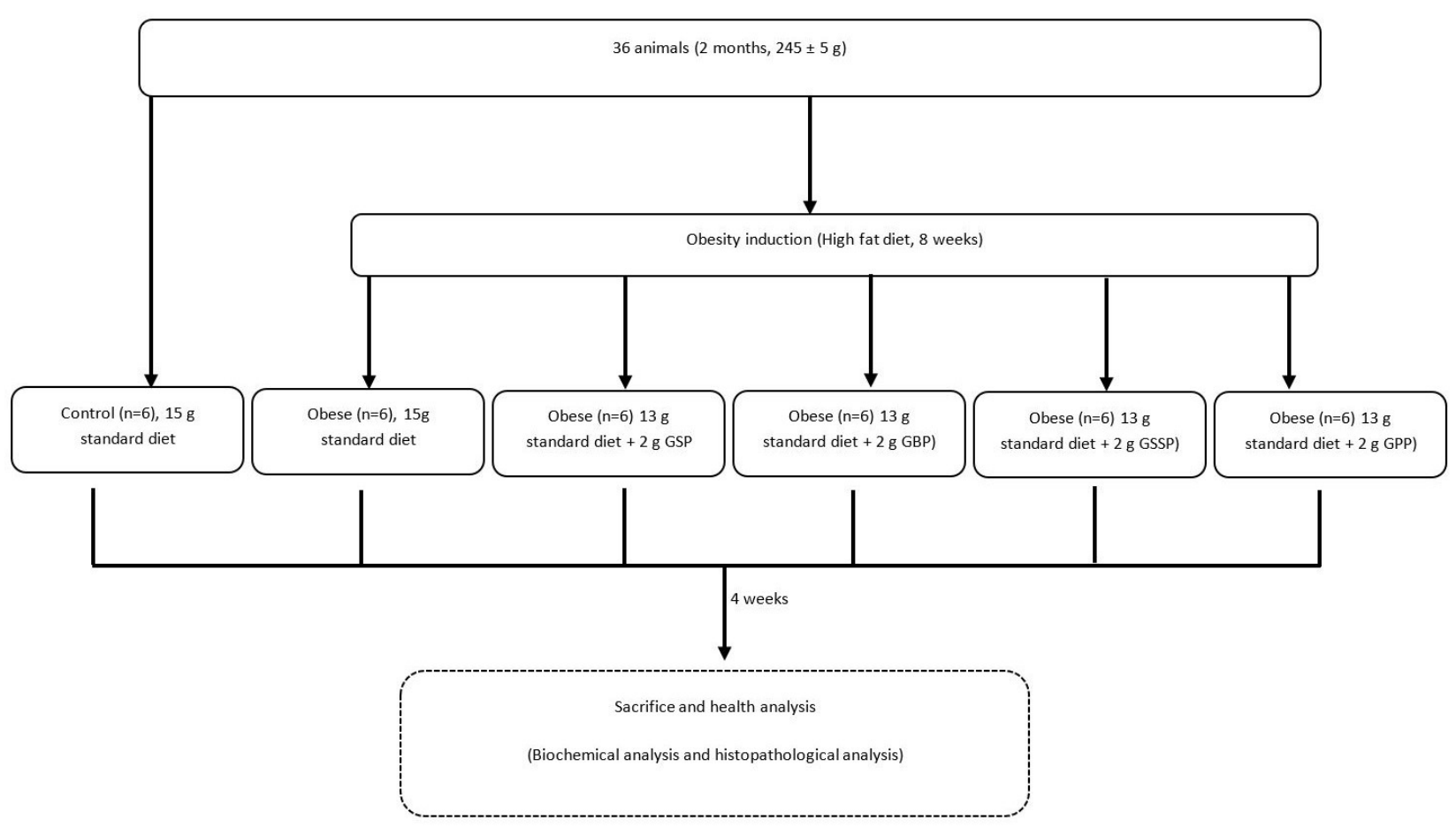

Figure 1. Distribution of groups and experimental design. GSP = guava-strawberry puree; GBP = guava-blackberry puree; GSSP = guava-soursop fruit puree; GPP = guava-passion fruit puree. 


\subsection{Histopathological analysis}

The liver tissues were fixed in $10 \%$ neutral-buffered formalin ( $\mathrm{pH}$ 6.8) and embedded in paraffin. The tissues were sectioned with a microtome with $5 \mu \mathrm{m}$ thick and stained with haematoxylin and eosin (Al Sayed et al., 2016). Afterwards, the sections were analyzed by light microscope (Leica DME1359, Wetzlar, Germany) (60x).

\subsection{Statistical analysis}

The in vivo data are expressed as mean of three replicates \pm standard error (SE). Data were analyzed using one-way analysis of variance (ANOVA, p < 0.05) and mean comparisons using the least significant difference test $(\alpha=0.05)$. All statistical analyses were performed using the statistical software STATISTICA (v.10 StatSoft, Tulsa, OK).

\section{Results and discussion}

\subsection{Body weight}

The body weight of the experimental animals is presented in Table 1. The body weight of StD group was maintained without change $(p>0.05)$ until the end of the experiment. However, in the animals fed HF-StD for 8 weeks, total food intake increased, and therefore the body weight increased (15\%) as expected. Body weight increases when energy consumption exceeds energy expenditure as occurred in this experiment. After the fat content was reduced in the diet, and body weight was reduced by $16 \%$ to $24 \%$ in all obese groups fed with StD and a fruit puree $(\mathrm{Ob}-\mathrm{StD}+\mathrm{FP})$, coinciding with the decrease in their total food intake. The reduction in body weight can be attributed to consumption of fruit purees because body weight in the Ob-StD group did not decrease. StD+FP contained $\sim 13.81 \%$ dietary fiber, $\sim 10 \mathrm{mg} / \mathrm{g}$ of polyphenols and $\sim 5.15 \mathrm{mg} / \mathrm{g}$ of vitamin C (Supplement Table S1). The synergistic effect of dietary fiber/indigestible fraction and phenolic compounds has been demonstrated in modulation of the inflammatory processes of adipose tissue (Moyano et al., 2016). Therefore, it is possible that the fruit purees, with an important indigestible fraction and bioactive compounds, caused beneficial effects, such as reduction in fat and carbohydrate absorption and a satiogenic effect, and may have the ability to activate thermogenesis and inflammatory processes (Moyano et al., 2016), decreasing the body weight of obese rats.

\subsection{Biochemical markers}

The content of TC, TG, HDL-C, VLDL-C, and LDL-C is shown in Table 1. A higher content of TC, LDL-C, VLDL-C and TG $(\mathrm{p}<0.05)$ was found in the obese experimental group (Ob-StD) than in all other groups. The initial consumption of HF-StD may cause an increase in free fatty acids, which are raw material for the manufacture of TG, LDL-C, VLDL-C, and a decrease in HDL-C, even though the diet was changed to normal StD after 8 weeks (Mejia de Grubb et al., 2017). The Ob-StD+FP groups registered a high reduction of TC (59-68\%), LDL-C (65-89\%), VLDL-C (61-82\%) and TG (61-82\%) in comparison with the Ob-StD group, but with similar values to the healthy control group (StD). The results were dependent on the kind of fruit puree. It was clear that the additional consumption of fruit purees caused notable changes in the lipid profile in obese animals probably due to the functional effect of the bioactive compounds in the four formulations (Pérez-Beltrán et al., 2017). It has been reported that some flavonoids participate in the reduction of fat absorption due to inhibition of the action of pancreatic lipases (Glisan et al., 2017). In addition, they can modify lipoprotein metabolism by inducing the elimination of hepatic cholesterol and causing an increase in the excretion of bile acids; in particular, proanthocyanins are considered to exert the main mechanisms of action in relation to the lipid profile (Dongiovanni et al., 2016). The HDL-C content was higher in the StD group than in obese groups fed or not with fruit purees. HDL-C is responsible for the transport of TG to be deposited and processed in the liver, and its concentration in serum should be higher to regularize its function when an individual is health (Glisan et al., 2017). However, an increase in the concentration of hepatic free cholesterol in the obese groups at least for the 8 weeks that they were fed with HF-StD, could affect in liver pathogenesis as a result of the accumulation of

Table 1. Body weight and changes in the lipid profile for healthy animals fed with standard diet (StD), obese animals fed with standard diet (Ob-StD), and obese animals fed with standard diet and guava-strawberry (Ob-StD+GSP), guava-blackberry (Ob-StD+GBP), guava-soursop fruit $(\mathrm{Ob}-\mathrm{StD}+\mathrm{GSSP})$, or guava-passion fruit $(\mathrm{Ob}-\mathrm{StD}+\mathrm{GPP})$ puree.

\begin{tabular}{|c|c|c|c|c|c|c|}
\hline Parameters & StD & Ob-StD & $\mathrm{Ob}-\mathrm{StD}+\mathrm{GSP}$ & Ob-StD+GBP & Ob-StD+GSSP & $\mathrm{Ob}-\mathrm{StD}+\mathrm{GPP}$ \\
\hline \multicolumn{7}{|l|}{ Body weight (g) } \\
\hline Initial & $245.0 \pm 4.6^{\mathrm{aX}}$ & $247.3 \pm 7.0^{\mathrm{ax}}$ & $251.0 \pm 6.4^{\mathrm{ax}}$ & $241.0 \pm 9.5^{\mathrm{ax}}$ & $238.0 \pm 2.0^{\mathrm{ax}}$ & $245.0 \pm 3.1^{\mathrm{ax}}$ \\
\hline After induction of obesity & $236.0 \pm 13.9^{\mathrm{aX}}$ & $302.7 \pm 5.7^{\mathrm{bY}}$ & $297.0 \pm 2.0^{\mathrm{bY}}$ & $299.0 \pm 11.1^{\mathrm{bY}}$ & $292.0 \pm 5.6^{\mathrm{bY}}$ & $294.3 \pm 6.7^{\text {bY }}$ \\
\hline End of treatment & $248.0 \pm 9.1^{\mathrm{ax}}$ & $300.3 \pm 1.5^{\mathrm{bY}}$ & $252.0 \pm 15.0^{\mathrm{cX}}$ & $228.0 \pm 4.4^{c Z}$ & $241.7 \pm 3.8^{\mathrm{cx}}$ & $249.3 \pm 9.6^{\mathrm{cX}}$ \\
\hline Total food intake (g per 60 days) & $836.0 \pm 4.6^{\mathrm{d}}$ & $1056.7 \pm 4.2^{\mathrm{a}}$ & $939.7 \pm 2.5^{\mathrm{b}}$ & $929.3 \pm 1.5^{\mathrm{b}}$ & $898.7 \pm 1.5^{c}$ & $935.7 \pm 5.1^{\mathrm{b}}$ \\
\hline \multicolumn{7}{|l|}{ Lipid profile (mmol/L) } \\
\hline Total cholesterol & $2.27 \pm 0.58^{\mathrm{b}}$ & $6.34 \pm 0.62^{\mathrm{a}}$ & $2.61 \pm 0.43^{\mathrm{b}}$ & $2.24 \pm 0.68^{\mathrm{b}}$ & $1.98 \pm 0.25^{\mathrm{b}}$ & $2.04 \pm 0.25^{\mathrm{b}}$ \\
\hline LDL-cholesterol & $0.17 \pm 0.50^{c}$ & $2.51 \pm 0.46^{\mathrm{a}}$ & $0.89 \pm 0.12^{\mathrm{b}}$ & $0.30 \pm 0.04^{c}$ & $0.28 \pm 0.25^{\mathrm{c}}$ & $0.40 \pm 0.19^{c}$ \\
\hline VLDL-cholesterol & $0.25 \pm 0.06^{c}$ & $1.24 \pm 0.02^{\mathrm{a}}$ & $0.23 \pm 0.25^{\mathrm{bc}}$ & $0.64 \pm 0.21^{\mathrm{b}}$ & $0.55 \pm 0.02^{\mathrm{b}}$ & $0.48 \pm 0.04^{\mathrm{b}}$ \\
\hline Triacylglycerols & $0.47 \pm 0.10^{c}$ & $2.72 \pm 0.05^{\mathrm{a}}$ & $0.50 \pm 0.05^{c}$ & $1.44 \pm 0.45^{\mathrm{b}}$ & $1.21 \pm 0.05^{\mathrm{b}}$ & $1.05 \pm 0.10^{\mathrm{b}}$ \\
\hline HDL-cholesterol & $1.09 \pm 0.12^{\mathrm{a}}$ & $0.8 \pm 0.03^{\mathrm{b}}$ & $0.66 \pm 0.09^{\mathrm{b}}$ & $0.54 \pm 0.60^{\mathrm{ab}}$ & $0.53 \pm 0.09^{\mathrm{b}}$ & $0.55 \pm 0.18^{\mathrm{b}}$ \\
\hline
\end{tabular}

The values represent the mean \pm standard error. Different lowercase letters $(\mathrm{a}, \mathrm{b}, \mathrm{c}, \mathrm{d})$ indicate significant differences $(\mathrm{p}<0.05)$ between treatments and uppercase letters $(\mathrm{X}, \mathrm{Y}, \mathrm{Z})$ indicate significant differences $(\mathrm{p}<0.05)$ between time of treatments. 
cholesterol, which is toxic at different levels, causing oxidative damage to the mitochondria, stress in the endoplasmic reticulum and activation of Kupffer cells. These changes trigger the inflammatory processes causing cell apoptosis and a decrease in the production and excretion of metabolites necessary for the homeostasis of the organism (Pacifico et al., 2014). Thus, the addition of fruit purees to the diet of obese rats decreased body weight gain and the levels of TC, TG, VLDL-C, and LDL-C but did not increase HDL-C levels. Sarfraz et al. (2019) and Moura et al. (2016) demonstrated that prebiotic dairy foods (dairy dessert and symbiotic yoghurt) reduced TG, LDL and
VLDL (8-10\% and 64.07-80.20\%, respectively); therefore, the fruit purees have a similar effect that prebiotic dairy foods in the lipid profile. The authors also concluded that significant significant reduction in TC, TG, LDL and VLDL could also be due to cholesterol assimilation or its deconjugation of bile acids, reducing digestibility of lipids.

The enzyme activities of AST, ALT, GGT, and AP are shown in Figure 2. Serum AST activity in the healthy control group (StD) was 98.2 U/L, whereas in obese animals (the Ob-StD group), serum AST activity increased to $151.3 \mathrm{U} / \mathrm{L}$ (Figure 2a). The alteration of lipids can generate insulin resistance and trigger the phenomenon
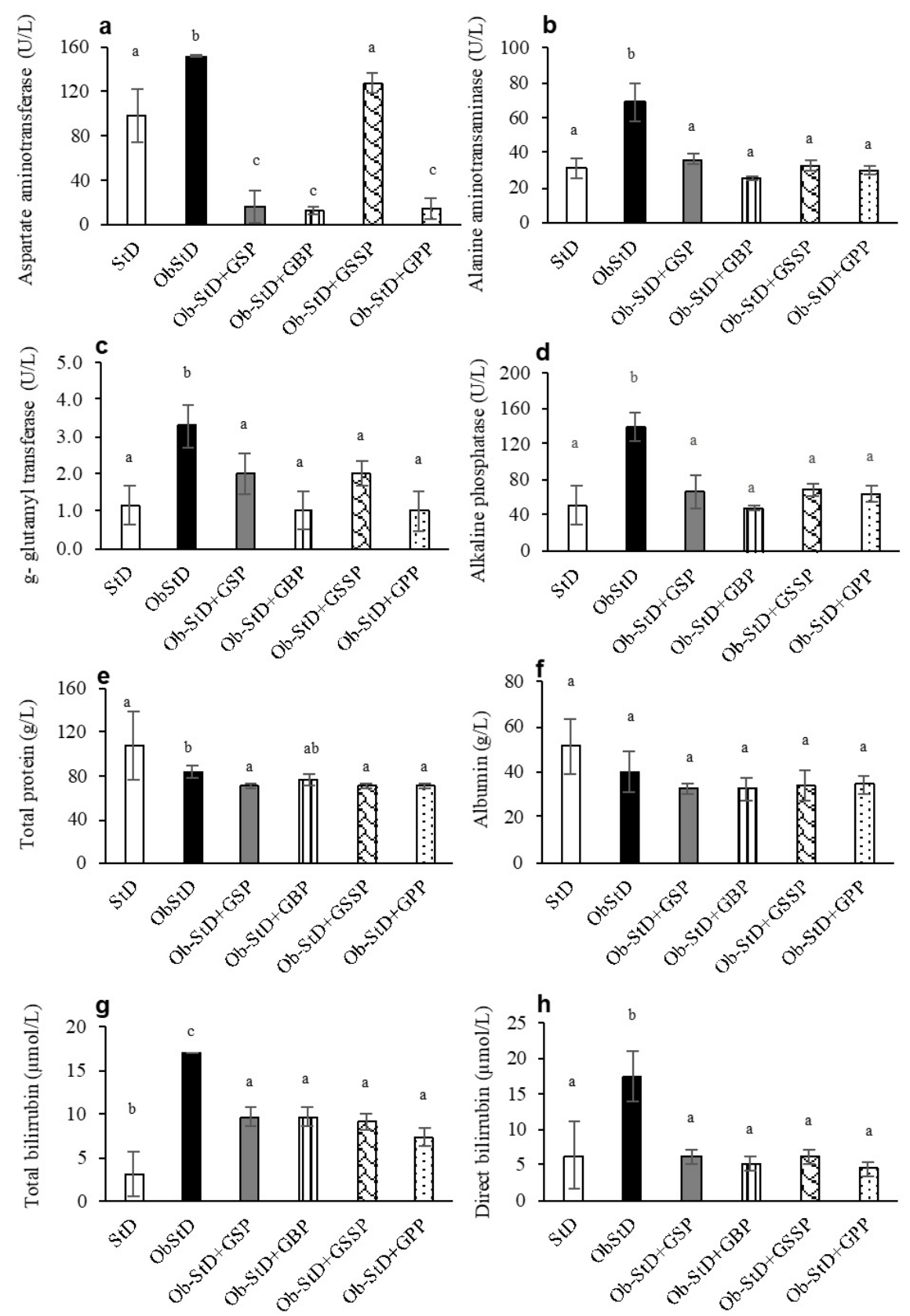

Figure 2. Aspartate aminotransferase (a), alanine aminotransaminase (b), $\gamma$-glutamyl transferase (c), and alkaline phosphatase (d) activities; total protein (e), albumin (f), total bilirubin (g), and bilirubin direct (h) in healthy rats fed with standard diet (StD), obese rats fed with StD (Ob-StD) and obese rats fed with StD plus guava-strawberry (Ob-StD+GSP), guava-blackberry (Ob-StD+GBP), guava-soursop fruit (Ob-StD+GSSP), or guava-passion fruit (Ob-StD+GPP) puree. Different lowercase letters in each bar indicate significant differences $(\mathrm{p}<0.05)$. 
of lipotoxicity, which cause decoupling of the cellular metabolism with the generation of signaling cascades that are related to the initiation of programmed cell death processes as well as high AST activity (Maulucci et al., 2016). When obese rats were fed with StD and a fruit puree such as GSP, GBP, GSSP, or GPP, the serum AST activity decreased to 15.8 (89.5\%), 12.1 (92\%), $126.8(16 \%)$ and $14.6 \mathrm{U} / \mathrm{L}(90.3 \%)$, respectively. This means that GSP, GBP, and GPP induced a higher decrease in AST activity than GSSP. It has been demonstrated that polyphenols have a direct relationship with the concentration of histone deacetylase enzymes (at DNA level) present in hepatocytes and therefore they have hepatoprotective activity because they inhibit the cycle that leads to cellular apoptosis (Vahid et al., 2015). In this way, the bioactive compounds in the fruit purees could influence the decrease in AST activity. The results for ALT activity are shown in Figure 2b. Serum ALT activity was high (68.8 U/L) in the Ob-StD group compared with the StD group (31.1 U/L). High serum ALT activity in the Ob-StD group indicated that there was damage to the liver due to free radicals or to the effect of pro-inflammatory factors secreted by adipose tissue, such as IL-6, IL-10 and TNF- $\alpha$, causing an increase in serum ALT activity (Moyano et al., 2016; Oliveira et al., 2016). Nevertheless, serum ALT activity decreased in obese groups fed with StD and GSP, GBP, GSSP, or GPP puree; the percentage reduction was $47.8 \%$, $62.8 \%, 53.2 \%$, and $56.5 \%$, respectively $(\mathrm{p}<0.05)$. This indicated that the consumption of fruit purees had a significant effect on the decrease in ALT activity, probably due to the content of bioactive compounds in the purees. Gallic acid has been reported to increase the expression of genes that synthesize antioxidant enzymes, such as SOD and CAT; modulate the expression of molecules that cause inflammation; and induce the expression of genes involved in cell proliferation, all contributing to a hepatoprotective effect, if the ALT activity in the liver is low (Oliveira et al., 2016). The fruit purees contained different polyphenols, including gallic acid (Pérez-Beltrán et al., 2017). Serum GGT and ALP activities are shown in Figure $2 \mathrm{c}$ and $2 \mathrm{~d}$. Serum GGT activity was higher in the Ob-StD group (3.3 U/L) than in all other groups $(1.0-2.0 \mathrm{U} / \mathrm{L})$. This enzyme is found particularly in the bile canaliculi, therefore an increase in its concentration indicates biliary obstruction as probably occurred in the Ob-StD group. Serum ALP activity was also higher in the Ob-StD group (139.4 U/L) than in the StD group $(51.1 \mathrm{U} / \mathrm{L})$ or the Ob-StD+FP groups (47.6-68.2 U/L). It has been reported that fatty acids can be cytotoxic per se when their metabolic regulation is inadequate with pathophysiologic consequences, such as induction of liver damage (Houben et al., 2017), as probably occurred in the Ob-StD group as shown by high
ALP activity. The low serum GGT and ALP activities in the Ob-StD+FP groups are related to an anti-inflammatory effect of the bioactive compounds present in the functional food matrix (Shahidi \& Ambigaipalan, 2015). It has been reported that this effect is counteracted by the action of bioactive compounds such as flavonoids (catechins, quercetins and isoflavones) present in the fruit matrix. The beneficial effect of these flavonoids has been reported to be due to suppression of the secretory route of pro-inflammatory interleukins (Moyano et al., 2016; Oliveira et al., 2016).

Table 2 shows the plasma glucose concentration. There was a marked increase in glucose in the Ob-StD group with a significant difference ( $\mathrm{p}<0.05$ ) compared with the StD group. One of the physiopathologic aspects of obesity is the effect produced by free fatty acids in plasma, which are regulated by insulin; however, during insulin resistance, these fatty acids increase and produce lipotoxicity in different organs such as the pancreas and liver, causing changes in the function of insulin receptors. It is possible that the high plasma glucose concentration in obese rats caused dyslipidemia and dyslipoproteinemias (Dongiovanni et al., 2016). However, plasma glucose decreased between $25 \%$ and $28 \%$ after 8 weeks of treatment in the Ob-StD+FP groups. Several studies have reported effectiveness of ingesting guava extracts to reduce hyperglycemia in obese rats (Eidenberger et al., 2013). The authors concluded that guava contains bioactive compounds with the potential to inhibit the dipeptidyl peptidase IV enzyme (DP-IV), which is responsible for degradation of incretin hormones such as glucagon-like peptide (GLP-1). The inhibition of DP-IV contributes significantly to insulin secretion and decreases glucagon secretion, thereby controlling plasma glucose concentrations (Noratto et al., 2015). The urea and uric acid levels were 9.27 and $0.16 \mathrm{mmol} / \mathrm{L}$ in the StD group, 10.47 and $0.17 \mathrm{mmol} / \mathrm{L}$ in the $\mathrm{Ob}-\mathrm{StD}$ group, respectively; with a tendency to decrease in the $\mathrm{Ob}-\mathrm{StD}+\mathrm{FP}$ groups (6.10-8.37 and 0.09-0.14 mmol/L, respectively; $\mathrm{p}<0.05)$. Although there was a significant difference $(\mathrm{p}<0.05)$ among the experimental groups, all values were normal for the healthy individuals. The creatinine levels also showed a decrease in the $\mathrm{Ob}-\mathrm{StD}+\mathrm{FP}$ groups in comparison with the $\mathrm{Ob}-\mathrm{StD}$ group. It is possible that, in the $\mathrm{Ob}-\mathrm{StD}+\mathrm{FP}$ groups, there was an improvement in renal activity, possibly by the action of bioactive compounds present in the purees. Bioactive compounds have a positive effect on reducing kidney failure (Oliveira et al., 2016). This suggests that there was no chronic damage in the kidneys and the renal elimination of these metabolites in the blood was adequate.

The concentration of albumin and total proteins (Figure $2 \mathrm{e}$ and $2 \mathrm{f}$ ) in the $\mathrm{Ob}-\mathrm{StD}+\mathrm{FP}$ and $\mathrm{Ob}-\mathrm{StD}$ groups had

Table 2. Biochemical parameters for healthy animals fed with standard diet (StD), obese animals fed with standard diet (Ob-StD), and obese animals fed with standard diet plus guava-strawberry (Ob-StD+GSP), guava-blackberry (Ob-StD+GBP), guava-soursop (Ob-StD+GSSP) or guava-passion fruit (Ob-StD+GPP) puree.

\begin{tabular}{lcrrrcc}
\hline \multicolumn{1}{c}{ Parameters } & StD & Ob-StD & Ob-StD+GSP & Ob-StD+GBP & Ob-StD+GSSP & Ob-StD+GPP \\
\hline Glucose $(\mathrm{mmol} / \mathrm{L})$ & $7.42 \pm 3.21^{\mathrm{b}}$ & $14.60 \pm 2.71^{\mathrm{a}}$ & $10.91 \pm 0.68^{\mathrm{b}}$ & $10.69 \pm 0.64^{\mathrm{b}}$ & $10.04 \pm 0.38^{\mathrm{b}}$ & $10.40 \pm 0.68^{\mathrm{b}}$ \\
Urea nitrogen $(\mathrm{mmol} / \mathrm{L})$ & $9.27 \pm 1.65^{\mathrm{a}}$ & $10.47 \pm 0.88^{\mathrm{a}}$ & $6.55 \pm 0.25^{\mathrm{b}}$ & $8.37 \pm 0.69^{\mathrm{ab}}$ & $6.10 \pm 1.17^{\mathrm{b}}$ & $6.82 \pm 1.18^{\mathrm{b}}$ \\
Uric acid $(\mathrm{mmol} / \mathrm{L})$ & $0.16 \pm 0.09^{\mathrm{b}}$ & $0.17 \pm 0.01^{\mathrm{a}}$ & $0.09 \pm 0.01^{\mathrm{c}}$ & $0.09 \pm 0.01^{\mathrm{c}}$ & $0.14 \pm 0.02^{\mathrm{b}}$ & $0.10 \pm 0.02^{\mathrm{bc}}$ \\
Creatinine $(\mu \mathrm{mol} / \mathrm{L})$ & $0.16 \pm 0.01^{\mathrm{b}}$ & $0.18 \pm 0.01^{\mathrm{a}}$ & $0.06 \pm 0.01^{\mathrm{c}}$ & $0.07 \pm 0.01^{\mathrm{c}}$ & $0.06 \pm 0.01^{\mathrm{c}}$ & $0.06 \pm 0.01^{\mathrm{c}}$ \\
\hline
\end{tabular}

The values represent the mean \pm standard error. Different superscript letters in the same line indicate significant differences $(\mathrm{p}<0.05)$. 
a tendency to decrease compared with the values for the $\mathrm{StD}$ group, however, there was no significant difference $(\mathrm{p}>0.05)$. Hypoalbuminemia can be caused by a decrease in protein synthesis as a result of liver diseases, which result in the inability of hepatocytes to synthesize this protein (Oettl et al., 2013). Although the obese animals consumed the fruit puree for 8 weeks, there was no increase in these parameters; but any change observed may be related to cell repair time (Oettl et al., 2013). The results for total and direct bilirubin are shown in Figure $2 \mathrm{~g}$ and $2 \mathrm{~h}$. The values were higher in the Ob-StD group than in the OStD+FP groups, which showed normal values as the StD group. Normal concentrations of total and direct bilirubin reflect a balance between hepatobiliary production and excretion; however, an increase in total bilirubin indicates intra- or extrahepatic obstructive processes, and high concentrations of direct bilirubin indicate narrowing of bile ducts causing inflammation. Both processes have been associated with pathologies such as obesity, diabetes mellitus type II, and metabolic syndrome, among others (Lee et al., 2017). The administration of antioxidant compounds through consumption of fruit purees was found to decrease tissue damage in rats due to neutralization of free radicals; therefore, if these radicals decrease, the concentration of both metabolites could also decrease as a result of repaired tissue (Pérez-Beltrán et al., 2017).

\subsection{Histopathological analysis}

The hepatocytes in the StD group, with normal chromic and uniform size, are shown in Figure 3a, demonstrating the physiomorphology of a healthy individual. Figure $3 \mathrm{~b}$ shows cells
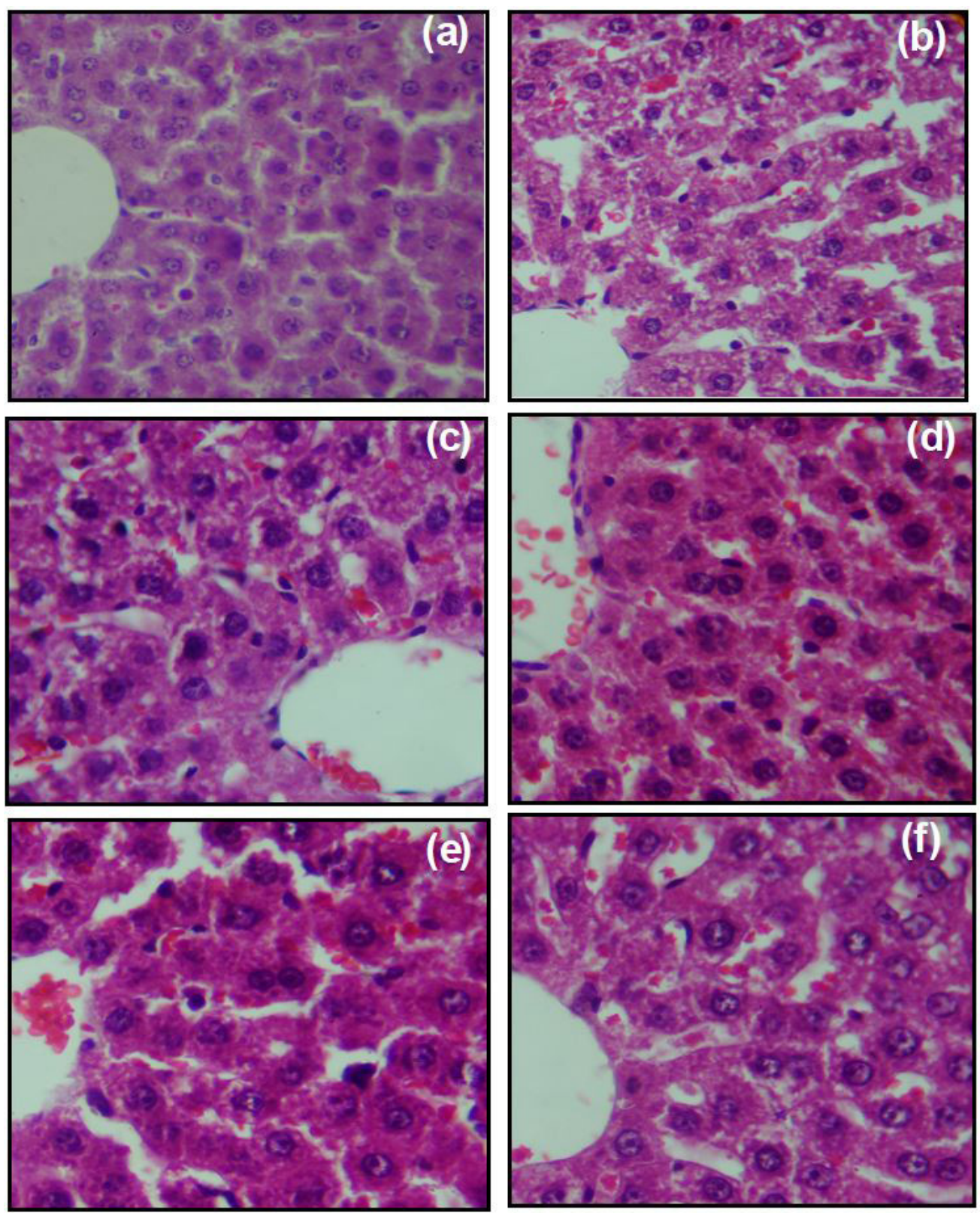

Figure 3. Histological photomicrographs of liver sections $(60 \times)$ in (a) healthy rats fed with standard diet (StD), (b) obese rats fed with StD, and obese rats fed with StD plus (c) guava-strawberry, (d) guava-blackberry (GBP), (e) guava-soursop fruit (GSSP), or (f) guava-passion fruit (GPP) puree. 
from the Ob-StD group with lesions triggered by hemodynamic changes in the circulatory system and severe damage in the hepatocytes with numerous lipid inclusions, decreasing their population. Recent studies have shown changes in focal nodular hyperplasia, one of the lesions related to obesity, involving vascular malformation composed of nodules of hyperplastic hepatocytes separated by fibrous septa, which can be seen under the microscope as scars (Wang, 2015), which was observed markedly in the liver of the Ob-StD group. Figures $3 \mathrm{c}-\mathrm{f}$ show changes in hepatic morphology with hepatocyte plaques directed from the portal triads to the ventral vein, homogeneous hepatocyte cells, normocytic and normochromic endothelial cells, and normal hepatic sinusoids, with clear tissue regeneration probably before induction to mitosis, because a greater number of nuclei can be observed in comparison with the Ob-StD group (Figure $2 \mathrm{~b}$ ). The potential effect of the addition of each puree to the diet was confirmed. The hepatoprotective effect of various compounds, such as resveratrol, epigallocatechin-3-gallate, quercetin, ellagitannins was reported at the DNA level, acting in a directly proportional relationship between the concentration of histone deacetylase enzymes and the population of hepatocytes (Vahid et al., 2015).

\section{Conclusions}

The additional consumption of fruit purees in the diet can decrease body weight in obese rats. The consumption of fruit purees for 8 weeks generated an anti-obesogenic and hepatoprotective effect in obese rats, demonstrated by a decrease in the concentration of markers of inflammation and liver damage, and improved liver morphology. The addition of fruit purees to a diet low in fat could be an alternative to help decrease body weight and chronic degenerative diseases in obese individuals.

\section{Acknowledgements}

This work was support by Tecnológico Nacional de Mexico (Grant n ${ }^{\circ}$. 6173.17-P) and CONACYT-Mexico (Grant no. 211953).

\section{References}

Al Sayed, N., Al Waili, K., Alawadi, F., Al-Ghamdi, S., Al Mahmeed, W., Al-Nouri, F., Al Rukhaimi, M., Al-Rasadi, K., Awan, Z., Farghaly, M., Hassanein, M., Sabbour, H., Zubaid, M., \& Barter, P. (2016). Consensus clinical recommendations for the management of plasma lipid disorders in the Middle East. International Journal of Cardiology, 225, 268-283. http://dx.doi.org/10.1016/j.ijcard.2016.09.081. PMid:27741487.

Ding, S., Du, Y., Lin, N., Su, Y., Yang, F., Kong, L., Ge, H., Pu, J., \& He, B. (2016). Effect of glucagon-like peptide-1 on major cardiovascular outcomes in patients with type 2 diabetes mellitus: a meta-analysis of randomized controlled trials. International Journal of Cardiology, 222, 957-962. http://dx.doi.org/10.1016/j.ijcard.2016.07.199. PMid:27526367.

Dongiovanni, P., Lanti, C., Riso, P., \& Valenti, L. (2016). Nutritional therapy for nonalcoholic fatty liver disease. The Journal of Nutritional Biochemistry, 29, 1-11. http://dx.doi.org/10.1016/j.jnutbio.2015.08.024. PMid:26895659.

Eidenberger, T., Selg, M., \& Krennhuber, K. (2013). Inhibition of dipeptidyl peptidase activity by flavonol glycosides of guava (Psidium guajava L.): a key to the beneficial effects of guava in type II diabetes mellitus.
Fitoterapia, 89, 74-79. http://dx.doi.org/10.1016/j.fitote.2013.05.015. PMid:23707747.

Encuesta Nacional de Salud y Nutrición - ENSANUT. (2016). Retrieved from http://www.oment.uanl.mx/cifras-de-sobrepeso-y-obesidaden-mexico-ensanut-mc-2016/

Glisan, S. L., Grove, K. A., Yennawar, N. H., \& Lambert, J. D. (2017). Inhibition of pancreatic lipase by black tea theaflavins: comparative enzymology and in silico modeling studies. Food Chemistry, 216, 296-300. http://dx.doi.org/10.1016/j.foodchem.2016.08.052. PMid:27596423.

Houben, T., Brandsma, E., Walenbergh, S. M. A., Hofker, M. H., \& ShiriSverdlov, R. (2017). Oxidized LDL at the crossroads of immunity in non-alcoholic steatohepatitis. Biochimica et Biophysica Acta. Molecular and Cell Biology of Lipids, 1862(4), 416-429. http://dx.doi. org/10.1016/j.bbalip.2016.07.008. PMid:27472963.

Lee, S.-E., Lee, Y.-B., Jun, J. E., Jin, S.-M., Jee, J. H., Bae, J. C., \& Kim, J. H. (2017). Increment of serum bilirubin as an independent marker predicting new-onset type 2 diabetes mellitus in a Korean population. Nutrition, Metabolism, and Cardiovascular Diseases, 27(3), 234-240. http://dx.doi.org/10.1016/j.numecd.2016.10.003. PMid:27989511.

Maulucci, G., Daniel, B., Cohen, O., Avrahami, Y., \& Sasson, S. (2016). Hormetic and regulatory effects of lipid peroxidation mediators in pancreatic beta cells. Molecular Aspects of Medicine, 49, 49-77. http:// dx.doi.org/10.1016/j.mam.2016.03.001. PMid:27012748.

Mejia de Grubb, M. C., Levine, R. S., \& Zoorob, R. J. (2017). Diet and obesity issues in the underserved. Primary Care: Clinics in Office Practice, 44(1), 127-140. http://dx.doi.org/10.1016/j.pop.2016.09.014. PMid:28164812.

Moura, C. S., Lollo, P. C. B., Morato, P. N., Esmerino, E. A., Margalho, L. P., Santos-Junior, V. A., Coimbra, P. T., Cappato, L. P., Silva, M. C., Garcia-Gomes, A. S., Granato, D., Bolini, H. M. A., Sant'Ana, A. S., Cruz, A. G., \& Amaya-Farfan, J. (2016). Assessment of antioxidant activity, lipid profile, general biochemical and immune system responses of Wistar rats fed with dairy dessert containing Lactobacillus acidophilus La-5. Food Research International, 90, 275-280. http:// dx.doi.org/10.1016/j.foodres.2016.10.042. PMid:29195882.

Moyano, G., Sáyago-Ayerdi, S. G., Largo, C., Caz, V., Santamaria, M., \& Tabernero, M. (2016). Potential use of dietary fibre from Hibiscus sabdariffa and Agave tequilana in obesity management. Journal of Functional Foods, 21, 1-9. http://dx.doi.org/10.1016/j.jff.2015.11.011.

Noratto, G., Martino, H. S. D., Simbo, S., Byrne, D., \& MertensTalcott, S. U. (2015). Consumption of polyphenol-rich peach and plum juice prevents risk factors for obesity-related metabolic disorders and cardiovascular disease in Zucker rats. The Journal of Nutritional Biochemistry, 26(6), 633-641. http://dx.doi.org/10.1016/j. jnutbio.2014.12.014. PMid:25801980.

Norma Oficial Mexicana. (1999). NOM-062-ZOO-1999: especificaciones técnicas para la producción, cuidado y uso de los animales de laboratorio. México: UNAM. Retrieved from http://www.fmvz.unam.mx/fmvz/ principal/archivos/062ZOO.PDF

Oettl, K., Birner-Gruenberger, R., Spindelboeck, W., Stueger, H. P., Dorn, L., Stadlbauer, V., Putz-Bankuti, C., Krisper, P., Graziadei, I., Vogel, W., Lackner, C., \& Stauber, R. E. (2013). Oxidative albumin damage in chronic liver failure: relation to albumin binding capacity, liver dysfunction and survival. Journal of Hepatology, 59(5), 978983. http://dx.doi.org/10.1016/j.jhep.2013.06.013. PMid:23811308.

Oliveira, L. S., Thom, G. R., Lopes, T. F., Reichert, K. P., de Oliveira, J. S., da Silva Pereira, A., Baldissareli, J., da Costa Krewer, C., Morsch, V. M., Chitolina Schetinger, M. R., \& Spanevello, R. M. (2016). Effects of gallic acid on delta-aminolevulinic dehydratase activity and in the biochemical, histological and oxidative stress parameters in the liver and kidney of 
diabetic rats. Biomedicine and Pharmacotherapy, 84, 1291-1299. http:// dx.doi.org/10.1016/j.biopha.2016.10.021. PMid:27810786.

Pacifico, L., Bonci, E., Andreoli, G., Romaggioli, S., Di Miscio, R., Lombardo, C. V., \& Chiesa, C. (2014). Association of serum triglyceride-to-HDL cholesterol ratio with carotid artery intimamedia thickness, insulin resistance and nonalcoholic fatty liver disease in children and adolescents. Nutrition, Metabolism, and Cardiovascular Diseases, 24(7), 737-743. http://dx.doi.org/10.1016/j. numecd.2014.01.010. PMid:24656140.

Pérez-Beltrán, Y. E., Becerra-Verdín, E. M., Sáyago-Ayerdi, S. G., Rocha-Guzmán, N. E., García-López, E. G., Castañeda-Martínez, A., Montalvo-González, R., Rodríguez-Aguayo, C., \& Montalvo-González, E. (2017). Nutritional characteristics and bioactive compound content of guava purees and their effect on biochemical markers of hyperglycemic and hypercholesterolemic rats. Journal of Functional Foods, 35, 447-457. http://dx.doi.org/10.1016/j.jff.2017.06.022.

Sarfraz, F., Farooq, U., Shafi, A., Hayat, Z., Akram, K., \& Rehman, H. U. (2019). Hypolipidaemic effects of synbiotic yoghurt in rabbits.
International Journal of Dairy Technology, 72(4), 1-6. http://dx.doi. org/10.1111/1471-0307.12618.

Shahidi, F., \& Ambigaipalan, P. (2015). Phenolics and polyphenolics in foods, beverages and spices: antioxidant activity and health effects: a review. Journal of Functional Foods, 18, 820-897. http://dx.doi. org/10.1016/j.jff.2015.06.018.

Siri-Tarino, P. W., \& Krauss, R. M. (2016). The early years of lipoprotein research: from discovery to clinical application. Journal of Lipid Research, 57(10), 1771-1777. http://dx.doi.org/10.1194/jlr.R069575. PMid:27474223.

Vahid, F., Zand, H., Nosrat-Mirshekarlou, E., Najafi, R., \& Hekmatdoost, A. (2015). The role dietary of bioactive compounds on the regulation of histone acetylases and deacetylases: a review. Gene, 562(1), 8-15. http://dx.doi.org/10.1016/j.gene.2015.02.045. PMid:25701602.

Wang, K. (2015). Molecular mechanisms of hepatic apoptosis regulated by nuclear factors. Cellular Signalling, 27(4), 729-738. http://dx.doi. org/10.1016/j.cellsig.2014.11.038. PMid:25499978. 
Morales-Ávila et al.

\section{Supplementary Material}

Supplementary material accompanies this paper.

Table S1. Nutritional composition of the experimental diets ( $\mathrm{g} / 100 \mathrm{~g}$ fresh weight).

This material is available as part of the online article from http://www.scielo.br/cta 